2016-03

Living together in student

accommodation: performances,

boundaries and homemaking

Holton, Mark

http://hdl.handle.net/10026.1/4976

10.1111/area.12226

Area

Wiley

All content in PEARL is protected by copyright law. Author manuscripts are made available in accordance with publisher policies. Please cite only the published version using the details provided on the item record or document. In the absence of an open licence (e.g. Creative Commons), permissions for further reuse of content should be sought from the publisher or author. 


\title{
Living together in student accommodation: performances, boundaries and homemaking
}

\begin{abstract}
Recent discussions of the geographies of students have drawn attention to the trajectories of UK students electing to leave home for university. Whilst such debates recognise these important mobilities, little has been discussed as to how students interact within their termtime accommodation. Through a qualitative study of the living arrangements of UK students, this paper will demonstrate that much can be drawn from focusing upon the microgeographies of non-local students within their term-time homes. Student accommodation is more than simply somewhere to live. Student homes are intensely dynamic places, perhaps more so than family homes as they contain multiple, disconnected identities. This research contributes to research on the geographies of the home by unpacking how house-sharers in transition interact with each other, how they transfer their identities from one home to another, how they delineate their territory and whether they integrate or withdraw within their term-time accommodation. This paper will address this by exploring (1) how students negotiate their habitualised behaviours in shared spaces and (2) how these behaviours become spatialised through the configuration and maintenance of boundaries.
\end{abstract}

\section{Keywords}

Student geographies; Home; Student mobility; Interdependence; Studentification; Non-local students

\section{Introduction}

Interest in 'student geographies' has gained momentum since Smith's (2009) edited Themed Issue in Environment and Planning A introduced us to the ways in which student populations 
contribute towards the changing urban fabric of university towns and cities. This paper joins this debate by building upon a burgeoning corpus of research concerned with the domestic geographies of students (Andersson et al., 2012; Diehl et al., 2013; Holton, 2014). Previous work has reported much on the [im]mobilities of students as they consider residing in university managed (Hubbard, 2009; Smith and Hubbard, 2014) or privately rented (Sage et al., 2013) term-time accommodation, with insightful discussion of the impact studentification has had upon ‘town’ and ‘gown’ relations within UK university towns and cities (Smith, 2008; Munro and Livingston, 2011). Alongside this is a focus upon students' 'exclusive geographies' (Chatterton, 1999) and how students are placed within communities and the wider networks of the city (Munro et al, 2009). Furthermore, Chatterton (2010) and Smith and Hubbard (2014) have suggested that the neoliberalisation of HE has increased students' opportunities to choose alternative term-time living arrangements, with purpose built student accommodation more than doubling between 2007/08 and 2012/13 (from 46,390 to 108,155 respectively). However, despite this increased choice, there remains a persistent appetite for shared student housing with almost one third of students $(516,220)$ occupying rental properties in 2012/13 (Higher Education Statics Agency (HESA), 2014).

Responding to these debates, it is apparent that much of this literature considers the notion of the 'student home' without ever really engaging with it as a lived space in which students make, organise and perform social interactions. This raises questions as to how students negotiate their position within student accommodation and how these positions are geographically [re]defined over the duration of the degree. As Kenyon and Heath (2001) argue, the positive and negative experiences of living in student accommodation may influence how students choose to live as adults. Therefore, much can be drawn from unpacking the micro-geographies of students' term-time accommodation in order to understand how students’ domestic experiences may shape their future accommodation 
preferences and highlight how this may be extrapolated to include other, seemingly unconventional, house-sharers. The rest of the paper is divided into six sections. The next two sections will examine the literature pertaining to the geographies of youthful and student homes. After outlining the methods, sections five and six will explore (1) how students negotiate habitualised behaviours in shared spaces and (2) how these behaviours become spatialised through the configuration and maintenance of boundaries. The final section offers some concluding remarks which observe how youthful homes contribute to discussions of student geographies.

\section{Youthful homes}

Blunt and Dowling (2006) argue that connections between house and home are often assumed but not necessarily easily demonstrated, meaning our interpretations of what constitutes home can be partial and subjective. In the context of 'the place where one lives', homes exist both as material spaces and places of meaning, hinting at the delicate interplay between 'house' and 'home' (Blunt, 2005). Hence, “our homes - perhaps more than any other geographical locations - have strong claims to our time, resources and emotions” (Valentine, 2001; p. 71), suggesting homes require a vested interest or sense of belonging to transform them from properties into places of meaning (Gorman-Murray, 2007). Homes exist as primary sites for our identity expression and are individualised spaces which fundamentally relate to our everyday material encounters (Gorman-Murray, 2008). Through the art of place-making, the configuration of homes and their constituent material parts can either accord with or subvert particular social relations (Blunt and Dowling, 2006) emphasising how homes, and the practices carried out within them, are complex and multiscalar. 
In understanding the materiality of the home Saunders (1989) suggests that homes are simultaneously "object[s] of consumption [and] container[s] within which much consumption takes place” (p. 177). However, when exploring the materiality of the home in the context of youthful homes, this can be complicated, particularly when attempting to negotiate hierarchical power dynamics. While homes can be opportunistic places of escape, in which identities can be constructed and tested (Hopkins, 2010), they are not unmediated spaces for young people. The social negotiation of seemingly 'un-written rules' ascribed to households mean that homes are often configured in ways which restrict and control behaviours in accordance to the prescribed 'fit' of the household. The geography of the home can therefore be pliable for young people, particularly as they mature, with rooms taking on different usages and meanings as their position within the household changes (Lewis, 2011). The bedroom, for example, can be a space whereby tastes and identities are sharpened and experimented with away from the parental gaze (Hopkins, 2010). Hence, as Holdsworth and Morgan (2005) argue, it is vital to consider material and social realities along with ideological and symbolic meanings in order to piece together a more holistic understanding of what home is and means to young people.

\section{Student homes: living together?}

Typically, most UK students’ housing biographies (Rugg et al., 2004) follow a pattern of 'home to halls to rented housing', however, detailed UK-centric research into the interactions between students within term-time accommodation is limited (see Kenyon, 1999; Andersson et al., 2012; Taulke-Johnson, 2010 for notable exceptions). Instead, much of the research into student housing focuses upon students' accommodation preferences (Hubbard, 2009) and the wider tensions between 'town' and 'gown' (Hubbard, 2008). A more substantial literature is concerned with how students consider home in relation to mobility and how this impacts 
upon identity construction and social networks (e.g. Chow and Healey, 2008). Lahelma and Gordon (2003) suggest that the role of the home comes under a great deal of scrutiny as students make their transition into university:

"Home is a space that consists of physical places, social practices, and mental meanings for young people. All the aspects are evoked when they plan or dream about moving away from their parental home” (p. 377).

Kenyon and Heath (2001) suggest that such transitions present an important stage in the development of a young adult's identity, particularly through the attainment of different transferrable domestic skills. In a study of Danish undergraduates’ food behaviours, Blichfeldt and Gram (2013) suggest that students are: “not starting out in a vacuum, but are entangled in their parents' food practices” (p. 287), suggesting that students transfer learned behaviours from the familial home into their accommodation. However, while domesticity in student accommodation may be constructed in relation to the familial home, students must also [re]negotiate their pre-existing identities, routines and behaviours alongside those of their housemates (Chow and Healey, 2008). Kenyon (1999) argues that these relations create different and interactive iterations of the home (personal, temporal, social and physical homes), concluding that the transition from the family home to term-time accommodation and beyond is far from a linear process.

One of the more significant, and under-researched aspects of this cohabitation is how students form and negotiate house rules within their accommodation. As home is a deeply personal and individual phenomenon (Blunt, 2005), the combination of several different versions of home within a single property can be problematic. This can manifest in conflict and tension between housemates over housework, personal hygiene, noise and thoughtlessness (Kenyon and Heath, 2001). Within this, Kenyon (1999) suggests that student 
homes can represent a complex surrogate familial bond, with pseudo-parent/child positions being negotiated on a daily basis. This can be further complicated through the design and layout of privately rented housing, making interactions with other housemates difficult. For example, the proliferation of landlordism in UK university locations has led to student-letting practices which prioritise bed-space over communal areas (Rugg et al., 2004). Hence, a lack of shared space can compartmentalise the household, placing simple activities within the confines of the bedroom, including eating, studying and socialising with friends (Kenyon, 1999).Student households can therefore be fragmented environments containing multiple, disconnected individuals which may become highly pressurised for those living in close proximity (Taulke-Johnson, 2010; Andersson et al., 2012). Student accommodation is, however, more than simply somewhere to reside during term-time. Student homes are intensely dynamic places, rather more so than family homes as they contain multiple, disconnected identities. Further inquiry will be useful in unpacking how students interact with each other, how they transfer their identities from one home to another, how they delineate their territory and whether they integrate or withdraw within their term-time accommodation.

\section{Methodology}

This study comes from a larger piece of research concerned with university students' 'sense of place' within their term-time environment. A sample of University of Portsmouth students were surveyed and interviewed about their university experiences during the spring of 2012 and this interpretation of the research focuses specifically upon the results of the qualitative interviews. Thirty one 'walking interviews' were conducted with students in which they were accompanied on self-directed journeys around the city ${ }^{1}$. The walking interviews were useful as they captured encounters 'in the moment' and developed richer understanding of the

\footnotetext{
${ }^{1}$ For a more detailed account of the walking interviews see Holton and Riley (2014).
} 
identities, emotions and social relations which shape the nature of the students' responses (Kusenbach, 2003; Holton and Riley, 2014). What was interesting about these interviews was that, while the students engaged well with their surroundings, the relaxed process of walking and talking and the visual environmental prompts often steered conversations onto other aspects of their university lives. Crucial to the development of this paper was that all of the students made reference to their home lives during the interviews, with students discussing the complex ways in which they managed interactions within their home-spaces. Themes of hierarchies, homemaking and boundary maintenance were common among the responses and focused upon the diverse and shifting relationships the students had with their housemates. The participants were keen to articulate this complexity of their domestic arrangements during their interviews. This analysis draws upon the experiences of the twenty students who lived in rented term-time accommodation ${ }^{2}$. These interview participants were aged mainly below 21 (80 per cent), white (90 per cent), female (60 per cent), and British (85 per cent) which, while not reflecting an evenly represented dataset, is indicative of the findings of other studies (Holdsworth, 2006; Patiniotis and Holdsworth, 2005). The students had also made several residential moves during their degrees (see Table 1), emphasising the uniqueness of their housing biographies.

(Place Table 1 here)

\section{Dynamic Hierarchies}

Student homes differ from other shared domestic environments in that they are influenced by the heterogeneous lifestyles and backgrounds of their occupants. Various time-space routines contribute to the shaping of these hybridized living spaces in which the materiality of the home becomes influenced by both pragmatic and dynamic practices. For example, students

\footnotetext{
${ }^{2}$ All names have been anonymised
} 
may attempt to 'remake’ home according to their previous domestic biographies (Chow and Healey, 2008; Lahelma and Gordon, 2003), however, they may also be constrained in their homemaking opportunities through financial constraints, landlord-imposed regulations or poor maintenance (Lister, 2006).This research both supports and problematises these claims by highlighting how students in transition might make sense of their behaviours in relation to who they are sharing with. Berger and Luckmann (1991) suggest that disconnected individuals become connected through reciprocal interactions with taken-for-granted routines. However, this research suggests that this becomes more complicated in the shared arena, as the performance of certain behaviours and actions needed to be negotiated quickly in order to be accepted. This was often achieved through the formation of (and cooperation with) hierarchies:

"In general me and [my fiancé] naturally take quite a lead role, organising the housework and things like making sure we all share in buying washing up liquid and toilet rolls and I'm the one who has the record of who has bought what and how much we have spent. We organise the paying of the bills and set up the internet contract and [my course mate] is happy to let us do it as long as she knows what's going on. We also have a joint account and [housemate's] quite happy for us to say 'put a hundred and fifty pounds in the joint account' and he'll do it and leave it at that, he's not too fussed about the ins and outs of where the money's going and things” (Kay).

Kay's comment emphasises this dynamism within household hierarchies in which the housemates 'naturally' adopted their own roles based upon their previous experiences of domesticity. Hence, the students were not necessarily using the home to re-shape their identities but attempting to 'fit' themselves into the household. 
Nevertheless, these hierarchies can be fragile and susceptible to collapse if not attended to carefully. This was alluded to by Paul who joined an already established household in his second year:

"I know that the three guys had lived together last year. [...] It sort of feels like I'm sort of just the add-on. They're really close and I'm their mate but not really as close as that" (Paul).

While parallels may be drawn here with Cox and Narula's (2003) terms ‘quasi-family relations', or ‘false kinship’ - the unequal relationships between non-family members residing in a household, the complex and disconnected backgrounds of housemates presents a different set of problems for student households. As Kay’s earlier comments suggested, living together within a shared house can create various configurations of pseudo-parent/child roles. However, these positions can be assumed, performed and reinforced unevenly between housemates creating asymmetrical power balances in the home. Moreover, as these habitualised positions are self-prescribed and relational they can collapse if members of the house feel their behaviours are not valued or reciprocated, meaning housemates must go through the performance of negotiating and re-negotiating their actions on a daily basis. Nevertheless, while habitualised behaviours are vital for successful transitions (Blichfeldt and Gram, 2012), the following interview passage indicates how the participants struggled to relate to their housemates' different domestic practices:

“My mum always said that if something doesn't belong somewhere, put it where it belongs. But with this lot, they'll just leave it and leave it and it'll just pick at the back of my mind. 'I know that you see this every day so why can't you just do it!' So I clean and think 'you shouldn't do it' but it's been there for like three weeks now and it's 
irritating me. Every day I walk past it and think 'that's not meant to be there'. I have talked to one of them and she said 'yeah, I'll do it at my convenience”' (Carrie).

Carrie’s comment implies differences in what may be acceptable behaviours in the shared student home and how these differences may negatively impact upon the spatial interactions of the household. While this supports Andersson et al.'s (2012) suggestion that tensions can originate from a lack of familiarity with housemates, it could be suggested that individualised actions can contribute towards the collapse of the collective habitualisation of the household. As Taulke-Johnson (2010a) suggests:

“[...] just as the social dynamics dictated and shaped by university accommodation may encourage students’ acceptance of peer diversity, so they may conversely exacerbate tensions within and between individuals and groups living there” (p. 402).

Moreover, Farah's comment below suggests a misalignment between the expectations of housemates' behaviours and the realities of their performances:

“The guys I shared with were like 'that's clean for me'. No, it's not clean at all, you have to be efficient. When we got those inspections they would just take their things, their dirty dishes, put them in their rooms and lock them up and once the inspector had gone they'd take them back out and put them back in the kitchen and that was horrible” (Farah).

As Blunt (2005) stresses, the meanings behind home are deeply personal and individual. Therefore the combination of several different iterations of home within a single property can become problematic when relationships break down (Kenyon and Heath, 2001). This mean that shared student households can become less interdependent spaces based on negotiated and reciprocated roles (Lahelma and Gordon, 2008) and more fractured spaces within which 
activities are performed independently, and in spite of one another, hampering the sharing of the space.

\section{Boundary Making}

Common among the responses were discussions of how interactions between housemates became spatialised when discordant activities were attempted simultaneously. Unlike most other communal living arrangements, the hybridized nature of student homes subverts the material norms of more typical domestic settings (Blunt and Dowling, 2006). They provide a mixture of what Goffman (1959) terms front-stage (communal kitchens, lounges etc.) and back-stage spaces (private bedrooms) which are used to differing degrees by housemates:

"I like it in the evenings when we're cooking dinner and the hustle and bustle of eating together, that's like family time, we'll talk about what we've done today and things like that" (Liam).

Consequently, students appear to have a fairly free reign over their housing, choosing how and when to perform activities and how to engage with the communal spaces of the home. Communal spaces in student accommodation therefore, represent '24-hour spaces' (Clear et al., 2013), flexible environments within which inhabitants can perform their routines. While this flexibility may be thought dynamic, temporal and spatial tensions may also exist between housemates as they negotiate their, potentially incongruent, study/play lifestyles. If issues arise, these less-structured arrangements can lead to a reconfiguration of the household:

“We stopped using the lounge completely, we didn't socialise or interact. Like the person who put the TV there took it back into their room. The kitchen, we timed it so we were all cooking at different times, it was separate meals. There would be the barest communication, if we were passing in the kitchen, that sort of thing. No-one 
wanted to share stuff, it was a big issue when we should clean and who should clean what" (Tori).

The contrast between Liam's and Tori's comments illustrates what might happen to the spatial networks within shared homes if the bonds between house-sharers disintegrate. Student accommodation lacks the familial bonds of traditional homes, meaning when tensions arise, occupants retreat from communal areas back into the privacy of their bedroom, essentially partitioning themselves off from the rest of the house. As Sibley and Lowe (1992) suggest, domestic spaces operate on the maintenance of boundaries which are policed by powerful household members. Boundary maintenance can be established to regulate acceptable forms of behaviour and define appropriate uses of space. In most familial homes boundaries are instigated hierarchically, often by parents mapping out the domestic norms of the home (Lewis, 2011). Yet in the context of shared student houses such hierarchies are complex and poorly structured meaning power is not necessarily recognised (or legitimised) between sharers, particularly if occupants do not share complimentary values. Hence student homes, in which the occupants have become increasingly disconnected, may become separated units, with perfunctory communication and/or interaction between occupants, rather than the deep involvement of more connected households. As this suggests, dichotomous relationships may contribute to a stalemate which is reinforced by the maintenance of both physical and behavioural boundaries within shared households.

\section{Conclusion}

In conclusion, by incorporating discussions of youthful homes into the student geographies debate, this paper has argued for recognition of the complex social and spatial configurations of shared student properties. In doing so, this paper contributes to previous work by highlighting how habitualised behaviours are performed and negotiated and how this can 
influence spatial configurations of boundaries within student homes. As was alluded to at the beginning of this paper, young people very often enter into social negotiations of power with parents or guardians in the home. They configure material and social realities with ideological and symbolic meanings (Holdsworth and Morgan, 2005) to establish a complimentary 'fit' within the household. As this paper suggests, student accommodation can be a more complex living environment than other shared living spaces in that their arrangement comprises the performance of multiple and heterogeneous actors in a single space. The temporal and seasonal nature of student accommodation means that some housemates may never desire any meaningful connections as they may only be residing in a household for a short period of time. For example, within the context of the student participants, certain performances were negotiated through the implementation of hierarchies and self-prescribed roles which were often relational, and at times discordant, creating asymmetric relationships within the home. Behaviours in the student home are therefore highly individualised and capable of disrupting the collective habitualisations of the household.

That is not to say that students are the only actors in this story. The increased intensity of landlordism in university locations (Smith and Hubbard, 2014) and a persistent reliance on parents to contribute to the cost of term-time accommodation (Rugg et al, 2004) has influenced the ways in which students may view their housing. As this research has shown, this may contribute towards a gulf between housemates' interpretations of their student house. Hence understanding the dynamics of student housing means recognising the multiple iterations of 'home' which exist within them. This research has also revealed how shared student accommodation exists as hybrid spaces - flexible environments in which sharers regulate the appropriate use of space through the complex maintenance of physical and behavioural boundaries. The complex time-space routines which contribute to the '24-hour' 
household can create dynamic, yet unstable living arrangements. While this may exist in other domestic settings, the students' testimonials present a unique geography to these discussions, in that tensions over domestic [ir]responsibilities become highly spatialised in shared student homes with distorted power [im]balances creating fragmented and disconnected social units. Therefore, whilst shared accommodation might be assumed as the most appropriate environment for young undergraduates to learn the various social and domestic skills required to make the transition into 'adult' lives, this research has demonstrated that these skills are not acquired simply. Student households may comprise multifarious social spaces in which sharers must perform and manage complex negotiations between their familial past and their interdependent present in order to make and maintain successful domestic interactions with housemates.

\section{References}

Andersson J Sadgrove J and Valentine G 2012 Consuming campus: geographies of encounter at a British University Social and Cultural Geography 13 501-15

Berger PL and Luckmann T 1991 The social construction of reality: A treatise in the sociology of knowledge Penguin, London

Blichfeldt BS and Gram M 2013 Lost in translation? Student food consumption Higher Education 65 277-89

Blunt A 2005 Cultural geography: cultural geographies of home Progress in Human Geography 29 505-15

Blunt A and Dowling R 2006 Home Routledge , London 
Chatterton P 1999 University students and city centres: the formation of exclusive geographies. The case of Bristol, UK Geoforum 30 117-33

Chatterton P 2010 The student city: an ongoing story of neoliberalism, gentrification and commodification Environment and Planning A 42 509-14

Chow K and Healey M 2008 Place attachment and place identity: first year undergraduates making the transition from home to university Journal of Environmental Psychology 28 36272

Christie H 2007 Higher education and spatial (im)mobility: non-traditional students and living at home Environment and Planning A 39 2445-63

Christie H Munro M and Rettig H 2002 Accommodating students Journal of Youth Studies 5 209-35

Clear AK Hazas M Morley J Friday A and Bates O 2013 Domestic food and sustainable design: a study of university student cooking and its impacts CHI 2013: Changing Perspectives, session: Food and Health 2447-56

Cox R and Narula R 2003 Playing happy families: rules and relationships in au pair employing households in London, England Gender, Place and Culture 10 333-44

Diehl C Andorfer VA Khoudja Y and Krause K 2013 Not in my kitchen? Ethnic discrimination and discrimination intentions in shared housing among university students in Germany Journal of Ethnic and Migration Studies 39 1679-97

Goffman E 2012 The presentation of self in everyday life [1959] Contemporary Sociological Theory, 46-61 
Gorman-Murray A 2007 Contesting domestic ideals: queering the Australian home Australian Geographer 38 195-213

Gorman-Murray A 2008 Reconciling self: gay men and lesbians using domestic materiality for identity management Social and Cultural Geography 9 283-301

Higher Education Statistics Agency 2014 Free online statistics - students and qualifiers Higher Education Statistics Agency http://www.hesa.ac.uk/content/view/1897/239/

Holdsworth C 2006 “Don’t you think you're missing out, living at home?”: Student experiences and residential transitions Sociological Review 54 495-519

Holdsworth C and Morgan D 2005 Transitions in context: leaving home, independence and adulthood Open University Press, Maidenhead

Holton M 2014 The geographies of UK university halls of residence: examining students' embodiment of social capital Children's Geographies (ahead-of-print) 1-14

Holton M and Riley M 2014 Talking on the move: place-based interviewing with undergraduate students Area 46 59-65

Hopkins PE 2013 Young people, place and identity Routledge, London

Hubbard P 2008 Regulating the social impacts of studentification: a Loughborough case Environment and Planning A 40 323-41

Hubbard P 2009 Geographies of studentification and purpose-built student accommodation: leading separate lives? Environment and Planning A 41 1903-23 
Kenyon EL 1999 A home from home: students' transitional experiences of home in Chapman $\mathbf{T}$ and Hockney $\mathbf{J}$ eds Ideal homes? Social change and domestic life Routledge, London 84-95

Kenyon E L and Heath S 2001 Choosing This Life: narratives of choice amongst house sharers Housing Studies 16 619-37

Kusenbach M 2003 Street phenomenology: the go-along as ethnographic research tool Ethnography 4 455-85

Lahelma E and Gordon T 2003 Home as a physical, social and mental space: young people’s reflections on leaving home Journal of Youth Studies 6 377-90

Lahelma E and Gordon T 2008 Resources and (in(ter))dependence: young people’s reflections on parents Young 16 209-26

Lewis R 2011 Shutting the bathroom door in Holt L ed Geographies of children, youth and families: an international Perspective Routledge, London 67-80

Lister D 2006 Unlawful or just awful? Young people’s experiences of living in the private rented sector in England, Young, 14 141-55

Munro M and Livingston M 2011 Student impacts on urban neighbourhoods: policy approaches, discourses and dilemmas Urban Studies 49 1679-94

Munro M Turok I and Livingston M 2009 Students in cities: a preliminary analysis of their patterns and effects Environment and Planning A 41 1805-25

Patiniotis J and Holdsworth C 2005 ‘Seize that chance!’ Leaving home and transitions to higher education Journal of Youth Studies 8 81-95 
Rugg J Ford J and Burrows R 2004 Housing advantage? The role of student renting in the constitution of housing biographies in the United Kingdom Journal of Youth Studies 7 19-34

Sage J Smith D and Hubbard P 2013 New-build studentification: a panacea for balanced communities? Urban Studies 50 2623-41

Saunders P 1989 The meaning of 'home' in contemporary English culture Housing Studies 4 $177-92$

Sibley D and Lowe G 1992 Domestic space, modes of control and problem behaviour Geografiska Annaler, Series B Human Geography 189-98

Smith DP 2008 The politics of studentification and '(un)balanced' urban populations: lessons for gentrification and sustainable communities? Urban Studies 45 2541-64

Smith DP 2009 'Student geographies’, urban restructuring, and the expansion of higher education. Environment and Planning A, 41 1795-804

Smith DP and Holt L 2007 Studentification and ‘apprentice’ gentrifiers within Britain’s provincial towns and cities: the meaning of gentrification Environment and Planning A 39 $142-61$

Smith DP and Hubbard P 2014 The segregation of educated youth and dynamic geographies of studentification Area 46 92-100

Taulke-Johnson R 2010 Assertion, regulation and consent: gay students, flatmates, and the heterosexualisation of university accommodation space Gender and Education 22 401-17

Valentine G 2001 Social geographies: space and society Pearson, Harlow 